\section{The effect of communication on the legitimacy and performance of organizations}

\author{
Camilo Prado-Roman ${ }^{1}$ \\ Francisco Diez-Martin ${ }^{1}$ \\ Alicia Blanco-Gonzalez ${ }^{1}$ \\ ${ }^{1}$ Rey Juan Carlos University, Business Economics, Madrid, Spain
}

\begin{abstract}
Purpose - The aim of the investigation is to examine the effect of communication on the legitimacy and performance of organizations. The research framework was built based on Institutional Theory.

Design/methodology/approach - The data were collected from 613 surveys of patients and health personnel of public hospitals in Madrid (Spain) and analyzed through partial least squares structural equation modeling (PLS-SEM). The questionnaires were anonymous. No identification data or biomedical data were requested.

Findings - The results confirm the existence of a positive effect between communication and organizational legitimacy. They also indicate that the effect produced by communication on organizational performance is considerably greater than that produced by organizational legitimacy. The findings provide new knowledge on communication as an antecedent of organizational legitimacy. From a practical point of view, the research provides ideas on how hospital managers can improve their performance through communication management and organizational legitimacy.
\end{abstract}

Originality/value - New evidence of the effects of communication on the legitimacy and performance of organizations is provided. The effect and the predictive relevance of legitimacy in relation on the performance of organizations are also identified.

Keywords - Communication, legitimacy, performance, stakeholder, hospitals
Recebimento:

07/03/2019

Aprovação:

$02 / 11 / 2020$

Editor responsável:

Prof. Dr. João Maurício Gama

Boaventura

Avaliado pelo sistema:

Double Blind Review

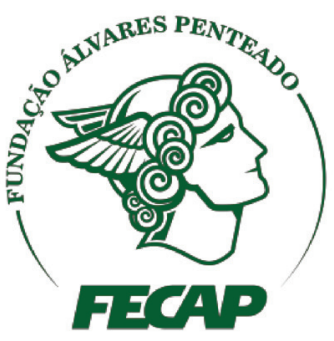

Revista Brasileira de Gestáo de Negócios

DOI:10.7819/rbgn.v22i3.4071 


\section{Introduction}

Communication management is essential for the governing of organizations because of its ability to influence individuals' behavior. The knowledge on this relationship has been widely developed in numerous research areas to solve different organizational problems. These problems range from attempting to achieve improvements in the internal functioning of organizations to seeking to improve external relations with clients and other stakeholders.

However, good communication does not always ensure successful organizational performance. There are numerous factors that can condition people's behavior regarding communication. For example, organizations have sometimes been involved in conflicts with society and as a result their legitimacy has been challenged (Palazzo \& Scherer, 2006). In uncertain environments, individuals eliminate or reduce the validity they give to communication channels when making decisions (Bitektine \& Haack, 2015). This leads to them questioning the credibility of the organization, even if the communication process is appropriate. A condition for organizational communication to have the desired impact is the existence of a relationship of trust with the stakeholders (Piber, Demartini, \& Biondi, 2019).

Institutional theory can help improve our understanding of the effect of communication on organizational performance. This theory indicates that organizations gain stakeholders' support when they show legitimacy (Choi \& Shepherd, 2005). Legitimacy is understood as "the perceived appropriateness of an organization to a social system in terms of rules, values, norms, and definitions" (Deephouse, Bundy, Tost, \& Suchman 2017 , p. 37). Thus, trusted organizations will have greater legitimacy (Piber et al., 2019) and greater access to the resources necessary to survive, thanks to their stakeholders' support (Brown, 1998). Organizational legitimacy is a key resource for the success and survival of organizations (Deephouse \& Suchman, 2008), and it has been proven that it is decisive for their survival (Ruef \& Scott, 1998). However, these authors point out that organizations should not behave like passive elements of the legitimization process. On the contrary, in order to achieve acceptance by their numerous stakeholders, they should develop actions that range from adjusting to established social models (for example, through isomorphism strategies) to manipulating the environment in which they operate (Oliver, 1991). Along these lines, researchers of Institutional Theory have paid special attention to the role played by communication in the legitimacy of organizations, especially the nature of communication when generating changes, as well as its contribution to the creation and maintenance of the institutional environment (Cornelissen, Durand, Fiss, Lammers, \& Vaara, 2015; Yim \& Park, 2019).

So far, researchers in the field of communication and legitimacy have focused on analyzing the role played by discourse and narrative management to influence evaluators' assessments regarding the achievement of organizational legitimacy. The impressions produced by these tools among the interested parties lead to the obtainment of legitimacy (Bansal \& Clelland, 2004). For example, some authors have analyzed the role of environmental disclosures as tools for acquiring legitimacy (e.g. Cho, Roberts, \& Patten, 2010; Deegan, 2002). Recently, it has been shown that corporate social responsibility (CSR) communication predicts legitimacy, because it makes organizations more credible (Lock \& Schulz-Knappe, 2019). Therefore, to improve their legitimacy with key stakeholders, corporations and large entities are increasingly revealing material information in integrated reports (Camilleri, 2018). In fact, the extent and quality of annual reports have a positive impact on organizational legitimacy (Aerts \& Cormier, 2009). 
Although previous studies have shown the existence of communication techniques that enhance legitimacy (e.g. discourse and narrative), the impact of communication on legitimacy is still unknown. How much does communication explain organizational legitimacy? Also, what is the predictive relevance of these variables to organizational outcomes?

The aim of the investigation is to examine the effect of communication on the legitimacy and performance of organizations. This research framework was built based on Institutional Theory (DiMaggio \& Powell, 1983; Meyer \& Rowan, 1977). Using this approach, the study contributes to the literature in several ways. Firstly, it provides new evidence of the size of the effect and the predictive relevance of communication in relation to the legitimacy and performance of organizations. Secondly, it identifies the effect and the predictive relevance of legitimacy in relation to the performance of organizations. From a practical point of view, the research provides ideas on how managers can improve their performance through communication management and organizational legitimacy.

\section{Literature Review and Hypotheses}

Communication can be understood as the social interaction by which oral and/or written messages are transmitted through speaking, gestures, speeches, texts, or other means. It is a continuous and at the same time dynamic process that contributes to the construction of organizations. Through the creation and manipulation of the meaning of messages and symbols, communication channels transmit cognitive contents and intentions between individuals. It is like a physical force that drives cognitive reactions between individuals (Ashcraft, Kuhn, \& Cooren, 2009). This makes it an essential process for the life and existence of organizations because it has a direct role in the company's general performance (Rapert \& Wren, 1998).

\section{I The effect of communication on organizational legitimacy}

Researchers of Institutional Theory suggest that studying the communication process in organizations has the potential to improve the wealth and explanatory power of theories and institutional models (Cornelissen et al., 2015). These researchers place the communication process at the center of Institutional Theory because they understand that institutions are the result of continuous communication processes between individuals. The interaction between individuals through the exchange of points of view leads to the building of a shared understanding of the organization and its environment (Dowling \& Pfeffer, 1975). Some authors have recognized that institutions exist and develop mainly through communication (McPherson \& Sauder, 2013).

From the legitimacy-as-process perspective (Suddaby, Bitektine, \& Haack, 2017), some researchers identify legitimization as a process of persuasion and influence for collective meaningmaking, based on language (Zilber, 2006) and communication (Suddaby, 2010). Organizations are social communities developed thanks to the communication between their members. Daily interaction between the organization's members leads to the formation of shared meanings (Walsh \& Ungson, 1991) composed of knowledge, culture, and social norms. This group of shared meanings determines what the desirable, appropriate, and acceptable beliefs, goals, and attitudes will be (Kersten, 1986). That is, they pave the way towards organizational legitimacy. Organizational legitimacy is a product of action, which is continually reproduced and reconstructed by members of an organization in concert with external legitimation activities (Drori \& Honig, 2013).

The role played by communication in organizational legitimacy has been analyzed previously (Camilleri, 2018; Vaara \& Tienari, 2008). Some authors have revealed that both companies that are more sensitive to 
environmental issues and those that are less sensitive to these issues use reports to disseminate their environmental results, as a tool to gain legitimacy (Cho \& Patten, 2007). Regarding discourse to obtain legitimacy, it has been observed that discourses related to the recognition of an action together with institutional characteristics obtain better legitimacy evaluations, compared to discourses made up of denials linked to technical characteristics (Elsbach, 1994). Other authors have identified the elements that make up the rhetorical strategies that lead to the legitimization of institutional changes (Suddaby \& Greenwood, 2005). It has also been observed that communication based on the narrative of historical data enhances organizational legitimacy (Golant \& Sillince, 2007). Recent research analyzes the role play by social networks in refocusing a crisis, regaining public confidence, building public opinion, cultivating relationships with stakeholders, and repairing legitimacy (Yim \& Park, 2019). In essence, it has been noted that communication is one of the essential elements in the legitimization process due to its ability to influence individuals' evaluations (Bitektine \& Haack, 2015). Communication is a tool that can be used to convey new ideas and values, for example, to generate a better understanding of priorities and strategic objectives. It can also be used to create environments that facilitate institutional changes or to cause changes in legitimacy assessments (Bitektine \& Haack, 2015; Díez-Martín, Blanco-González, \& Prado-Roman, 2018). This occurs because it is a source of validity, understood as "the extent to which there appears to be a general consensus within a collectivity that the entity is appropriate for its social context" (Tost, 2011, p. 689).

The better the communication is (more satisfactory, credible, continuous, transparent, and understandable), the greater the validity it transmits, and the greater its credibility and influence on individuals' judgments. Thus, given that validity has a strong effect on individuals' judgments, it is possible to persuade them to act or assume certain behaviors as their own, through communication conducted through both internal and external channels (Bitektine \& Haack, 2015). Communication is important to create a feeling of trust in order to satisfy the stakeholders and obtain legitimacy (Piber et al., 2019).

H1. Communication has a positive effect on organizational legitimacy.

\subsection{The effect of communication on organizational performance}

Communication forms the basis of what the organization is and determines how its members should behave. When there is no continuous communication within the company, the members' behavior becomes random and disorganized, which can lead to poor performance (Skivington \& Daft, 1991). On the contrary, frequent and constant communication helps build understanding inside and outside the organization. Frequent interactions/communications lead to the obtainment of similar perceptions, values, and beliefs (Chattopadhyay, Glick, Miller, \& Huber, 1999). This construction requires multiple seeds of understanding to be periodically sewn between all the organization's members (Rapert, Velliquette, \& Garretson, 2002).

Organizations with open communication environments, where there is continuous and free exchange of information between their members, tend to achieve higher results than organizations with more restrictive communication environments (Rapert \& Wren, 1998). It is a prerequisite for organizational performance (König, Fehn, Puck, \& Graf-Vlachy, 2017).

The relationship between communication and the performance of organizations has been studied in the strategic theory, where it has been identified that the convergence of an organization's members towards common attitudes and beliefs favors commitment (Ross, Anderson, \& Weitz, 1997) and strategic consensus (McDermott \& Boyer, 1999). That is, the perceived quality of organizational information and communication is associated with higher levels of strategic consensus (Desmidt \& George, 2016). In turn, the existence of strategic consensus influences the success of 
the implementation efforts of the organization's strategy (Noble, 1999) and, by extension, organizational performance (Siam, 2017).

H2. Communication has a positive effect on organizational performance.

\subsection{The effect of organizational legitimacy on organizational performance}

The importance of legitimacy to organizations has been explained extensively by institutionalists (Meyer \& Rowan, 1977), who have argued that legitimacy favors the survival of organizations (e.g. Hannan \& Carroll, 1992), such as hospitals (Ruef \& Scott, 1998). This has led researchers to attempt to understand the actions and behaviors that lead to the obtainment of legitimacy, such as the use of rhetoric (Suddaby \& Greenwood, 2005) or language (Cho et al. 2010). Beyond this, research has also been carried out to discover the effects of legitimacy on organizational performance (Díez-Martín, PradoRoman, \& Blanco-González, 2013).

In this last case, researchers have developed and contrasted hypotheses that predict how legitimacy influences a wide variety of performance measures. It has been demonstrated that organizational legitimacy influences: the financial results of banks (Deephouse, 1996); the price of shares (Gómez-Martínez, Andreu, \& DíezMartín, 2018; Lamin \& Zaheer, 2012); the value of initial public offerings (IPOs) (Bell, Filatotchev, \& Aguilera, 2013); return over assets (ROA) (Aerts \& Cormier, 2009), and unsystematic market risk (Bansal \& Clelland, 2004). In addition, legitimacy favors the emergence of new ventures (Tornikoski \& Newbert, 2007; Zimmerman \& Zeitz, 2002); the internationalization of companies (Kostova, Roth, \& Dacin, 2008); the proliferation of responsible strategies with regard to society (Scherer \& Palazzo, 2007); stakeholder management (Mitchell, Agle, \& Wood, 1997); and the purchase intention of consumers (Chaney, Lunardo, \& Bressolles, 2016).

These results can be explained by considering legitimacy as an asset, a resource that can be possessed and measured (Deephouse \& Suchman, 2008). Based on this vision of legitimacy as a property (Suddaby et al., 2017), it is understood that the most legitimized organizations get better access to the resources needed to survive (Becker-Blease \& Sohl, 2015; Chaney et al., 2016; Pollack, Rutherford, \& Nagy, 2012). This happens due to the greater capacity of legitimized organizations to influence stakeholders' behavior (Choi \& Shepherd, 2005).

H3. Legitimacy has a positive effect on organizational performance.

\subsection{Conceptual framework}

The research model shown in Figure 1 proposes that the better the communication in organizations, the greater the impact on their performance (Hypothesis 1) and legitimacy (Hypothesis 2); at the same time, the level of legitimacy of the organization will have a positive impact on its performance (Hypothesis 3).

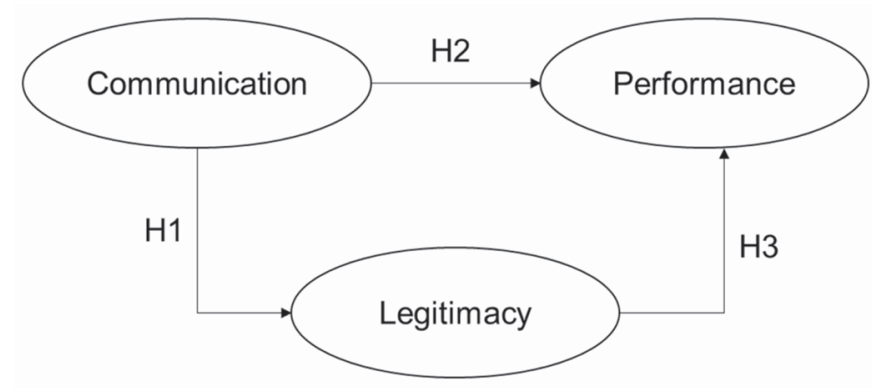

Figure. 1. Model of the effect of communication and legitimacy on performance. 


\section{Methodology}

\section{I Sample and data collection}

To verify the hypotheses proposed, a survey questionnaire was completed and filled out in person. This survey was carried out in September, October, and November of 2017 by means of a convenience sample composed of patients (aged 18 or over) and health personnel of the five main public hospitals (La Paz, Gregorio Marañon, 12 de Octubre, Ramón y Cajal, and Clínico San Carlos) of the Community of Madrid (Spain), which at that time represented 5,799 hospital beds in the region (84.45\%).

The data were obtained from public hospitals because the public hospitals field is strongly institutionalized, with significant similarity-producing mechanisms. The field is dominated by robust and historically permanent values and norms related to medical and healthcare professions. The choice of this population of hospitals was due to the fact that they have adopted the same health policies, regulations, guarantees, and laws imposed by the regional government, which is able to exert coercive pressures to achieve similar quality standards and patient care among hospitals, through common norms. These norms do not vary between hospitals and contribute to strengthening the field through normative pressures for similarity. Moreover, the working infrastructure among public hospitals from the same region is similar. They also share the same physical and cultural environment. As a result, communication mechanisms are similar, as is the need to maintain similar legitimacy standards in all their practices, in accordance with the institutional environment in which they operate.

A sample of 613 respondents completed the survey. The sample had the following characteristics: $72.43 \%$ were patients and $27.56 \%$ were health personnel; $42 \%$ of the respondents were between 18 and 30 years old, 40\% were between 31 and 45 years old, and 18\% were over 45; and $61.5 \%$ were female. Each respondent was instructed to complete a standard questionnaire which contained a series of questions regarding the variables of interest in the study. They were informed of the confidentiality of their views and opinions and debriefed after the survey. The questionnaires were anonymous. No identification data or biomedical data were requested.

\subsection{Variable measurement}

The research instrument of the study is an ad hoc questionnaire, based on the theoretical and empirical literature on business management and communication. Five-point Likert scales were used to measure each question (Appendix A).

Previous literature reveals several methodologies to measure organizational legitimacy. There are measurements based on media (Bansal \& Clelland, 2004) or regulators (e.g. Deephouse, 1996). Other measurements are based on individual perceptions (Alexiou \& Wiggins, 2018; Mártinez-Navalón, BlancoGonzález, \& Prado-Román, 2019). Some evaluations have measured the overall legitimacy of the organization (Chaney et al., 2016), while most research has measured it through its typologies (see Alexiou \& Wiggins, 2018). In the present case, organizational legitimacy was measured by using three dimensions. Studies on organizational legitimacy suggest that legitimacy is formed of numerous dimensions, which can be used to measure it (Bitektine, 2011; Díez-deCastro, Peris-Ortiz, \& Díez-Martín, 2018). In this research, legitimacy was measured through its pragmatic, moral, and cognitive dimensions, which are the most widely used in empirical studies that measure the legitimacy of organizations (Alexiou \& Wiggins 2018; Díez-Martín et al., 2013). Pragmatic legitimacy is achieved when the evaluators consider that the evaluated organization serves their interests and meets their expectations. Moral legitimacy is achieved when the values, beliefs, and ethical thinking of society is consistent with the culture and actions of the organization. Cognitive legitimacy is achieved when evaluators consider the organization to 
be understandable and its behavior is taken for granted (see Suchman, 1995).

To assess the perception of hospital communication, items that measure communication globally were used (ZwijzeKoning \& Jong, 2007). The items used focused on the measurement of internal and external communication. On the one hand, the quality of communication between employees and patients was measured. On the other hand, the quality of communication between hospital employees was gauged. The items used were similar to those proposed by other researchers such as Wynia and Osbron (2010).

The measure of hospital performance was self-developed based on a review of the literature (Chang, Tung, Huang, \& Yang, 2008; Dahlgaard, Pettersen, \& Dahlgaard-Park, 2011; Voelker, Rakich, \& French, 2001). Unlike other studies in which emphasis has been placed on patient care (Baird, Tung, \& Yu, 2017), in this research emphasis is placed on stakeholders' perception of overall hospital performance. The aim of the items used is to show the level of achievement of the objectives indicated for public hospitals of the national health system of Spain (Ministerio de Sanidad, 2016). Thus, aspects related to equality, quality, and efficiency are evaluated.

\subsection{Data analysis}

Table 1 shows the descriptive statistics of the model variables. To analyze the effect of communication on legitimacy and organizational performance, partial least squares (PLS), a variance-based structural equation modeling technique (Reinartz, Haenlein, \& Henseler, 2009), was used. This method allows for the assessment of the reliability and validity of the measures of the theoretical constructs and the estimation of the relationships between these constructs. PLS is an appropriate technique to use in a theory development situation such as in this study because: a) the model is formed of reflective and formative constructs; b) it is primarily intended for causal-predictive analysis, where the problems explored are complex and prior theoretical knowledge is scarce; c) the utilization of PLS is advisable for studies that use secondary data (Hair, Hult, Ringle, \& Sarstedt, 2017).

Table 1

\section{Measurement of variables and descriptive statistics}

\begin{tabular}{|c|c|c|c|c|c|c|c|c|c|c|c|c|c|c|}
\hline Dimension & $\begin{array}{l}\text { Item } \\
\text { ID }\end{array}$ & Mean & $\begin{array}{c}\text { Std. } \\
\text { Deviation }\end{array}$ & & & & & & orrelati & & & & & \\
\hline Communication & & & & Com 1 & Com 2 & Leg1 & Leg2 & Leg3 & Perf1 & Perf2 & Perf3 & Perf4 & Perf5 & Perf6 \\
\hline $\begin{array}{l}\text { Internal } \\
\text { communication }\end{array}$ & Com1 & 3,21 & 1,02 & 1,000 & 0,556 & 0,526 & 0,297 & 0,509 & 0,556 & 0,642 & 0,627 & 0,545 & 0,555 & 0,412 \\
\hline $\begin{array}{l}\text { External } \\
\text { communication }\end{array}$ & Com2 & 3,24 & 1,02 & & 1,000 & 0,484 & 0,234 & 0,535 & 0,503 & 0,555 & 0,620 & 0,524 & 0,594 & 0,447 \\
\hline \multicolumn{15}{|l|}{ Legitimacy } \\
\hline Pragmatic & Leg1 & 3,44 & 1,01 & & & 1,000 & 0,512 & 0,754 & 0,387 & 0,547 & 0,545 & 0,433 & 0,438 & 0,408 \\
\hline Moral & Leg2 & 3,43 & 1,21 & & & & 1,000 & 0,518 & 0,222 & 0,200 & 0,243 & 0,323 & 0,164 & 0,210 \\
\hline Cognitive & Leg3 & 3,43 & 1,05 & & & & & 1,000 & 0,468 & 0,590 & 0,640 & 0,449 & 0,428 & 0,414 \\
\hline \multicolumn{15}{|l|}{ Performance } \\
\hline & Perf 1 & 3,68 & 1,05 & & & & & & 1,000 & 0,629 & 0,577 & 0,397 & 0,517 & 0,351 \\
\hline & $\operatorname{Perf} 2$ & 3,49 & 1,05 & & & & & & & 1,000 & 0,712 & 0,474 & 0,535 & 0,408 \\
\hline & $\operatorname{Perf3}$ & 3,4 & 1,03 & & & & & & & & 1,000 & 0,519 & 0,594 & 0,424 \\
\hline & Perf4 & 3,23 & 1,05 & & & & & & & & & 1,000 & 0,449 & 0,423 \\
\hline & Perf5 & 3,35 & 1,01 & & & & & & & & & & 1,000 & 0,288 \\
\hline & Perf6 & 3,37 & 0,98 & & & & & & & & & & & 1,000 \\
\hline & & $\mathbf{N}=613$ & & & & & & & & & & & & \\
\hline
\end{tabular}




\section{Results}

The estimation of a model by means of PLS-SEM requires a two-step systematic evaluation (Hair et al., 2017). In the first step, the relationships between the indicators and the constructs (measurement models) are analyzed, and in the second step the relationships between the constructs (structural model) are assessed.

\section{I Assessment of the measurement model}

Tables 2 and 3 show the results for the evaluation of the measurement model. The model is formed of two reflective components (communication and legitimacy) and a formative component (performance). Regarding the evaluation of the reflective measurement model, internal consistency, convergent validity, and discriminant validity were evaluated.

Internal consistency reliability evaluates the accuracy of the indicators. Composite reliability and the Cronbach's alpha were used to evaluate it. According to Nunnally and Bernstein's (Nunnally \& Bernstein, 1994) guidelines regarding internal consistency reliability, all of the indicators were reliable. The results exceed the minimum values recommended in the literature $(>0.7$ and $<0.9)$.

Convergent validity evaluates to what extent an item is correlated with another item of the same construct. Convergent validity was assessed by examining the average variance extracted (AVE) (Hair, Ringle, \& Sarstedt, 2011). The AVE indicates the amount of variance that a construct obtains from its indicators in relation to the amount of variance due to the measurement error. The AVE measures for all latent variables were greater than 0.736 , which is more than the 0.5 threshold suggested for research settings (Hair et al., 2017).

Discriminant validity shows to what extent one construct is different from another and captures a phenomenon that is not represented by another model construct. Two methods were used to evaluate it: (a) the Fornell-Larcker criterion, which analyzes whether the correlations between the dimensions are lower than the square root of the AVE (Fornell \& Larcker, 1981), and (b) the heterotrait-monotrait (HTMT) ratio of correlations between two constructs (Henseler, Ringle, \& Sarstedt, 2015). All values were below the limit.

Regarding the evaluation of the formative measurement model, convergent validity, collinearity between indicators, and the significance and relevance of outer weight were evaluated (Hair et al., 2017). The convergent validity of the formative construct is supported by an $\mathrm{R}$ squared above the recommended minimum $(>0.64)$. The existence of collinearity problems was evaluated using the variance inflation factor (VIF). The values obtained were below the accepted minimum $(<5)$. Finally, the evaluation of the weights of the formative indicators showed significant estimates above the minimum required $(>0.50)$.

Table 2

\section{Reliability and convergent validity}

\begin{tabular}{|c|c|c|c|c|c|c|c|c|}
\hline Construct & Indicator & Loadings & Weights & T-value & CA & CR & AVE & VIF \\
\hline \multirow[t]{2}{*}{ Communication } & Com 1 & $0.89^{* * *}$ & & 98.53 & 0.71 & 0.88 & 0.78 & $\mathrm{n} / \mathrm{a}$ \\
\hline & Com 2 & $0.88^{* * *}$ & & 86.62 & & & & \\
\hline \multirow[t]{3}{*}{ Legitimacy } & Leg 1 & $0.92^{* * *}$ & & 138.3 & & & & \\
\hline & Leg 2 & $0.70^{* * *}$ & & 23.08 & 0.82 & 0.89 & 0.73 & $\mathrm{n} / \mathrm{a}$ \\
\hline & Leg 3 & $0.92^{* * *}$ & & 149.06 & & & & \\
\hline \multirow[t]{6}{*}{ Performance } & Perf 1 & & $0.12^{* * *}$ & 2.58 & & & & 1.85 \\
\hline & Perf 2 & & $0.24^{* * *}$ & 4.87 & & & & 2.45 \\
\hline & Perf 3 & & $0.29^{* * *}$ & 6.45 & $\mathrm{n} / \mathrm{a}$ & $\mathrm{n} / \mathrm{a}$ & $\mathrm{n} / \mathrm{a}$ & 2.55 \\
\hline & Perf 4 & & $0.29^{* * *}$ & 6.82 & & & & 1.55 \\
\hline & Perf 5 & & $0.24^{* * *}$ & 5.11 & & & & 1.73 \\
\hline & Perf 6 & & $0.17^{* * *}$ & 4.65 & & & & 1.34 \\
\hline
\end{tabular}

$\mathrm{CA}=$ Cronbach's alpha; $\mathrm{CR}=$ Composite reliability; $\mathrm{AVE}=$ Average variance extracted; $\mathrm{VIF}=$ Variance inflation factor $\mathrm{n} / \mathrm{a}=$ not applicable

${ }^{* * *} \mathrm{p}<0.01$ 
Table 3

Discriminant validity

\begin{tabular}{lccc}
\hline & Communication & Legitimacy & Performance \\
\hline Communication & 0.882 & 0.764 & $\mathrm{n} / \mathrm{a}$ \\
Legitimacy & 0.602 & 0.852 & $\mathrm{n} / \mathrm{a}$ \\
Performance & 0.825 & 0.654 & 1 \\
\hline
\end{tabular}

Note: Main diagonal values are square root of the AVE; above the main diagonal is the HTMT ratio; below the main diagonal are the correlations between constructs.

\subsection{Assessment of the structural model}

The results of the assessment of the structural model can be observed in Table 4. A bootstrapping method (5000 subsamples) was used to generate standard errors and t-statistics. This allows us to assess the statistical significance of the path coefficients. All the relationships in the proposed model were significant and their values were above those recommended ( $>0.3)$.

Table 4

\section{Results of hypothesis testing}

\begin{tabular}{lccc}
\hline Hypothesis & $\begin{array}{c}\text { Path coefficients } \\
\text { (standarized ( ) }\end{array}$ & $\begin{array}{c}\text { t-value } \\
\text { (bootstrap) }\end{array}$ & $\mathbf{f}^{\mathbf{2}}$ \\
\hline H1. Communication --> Legitimacy & $0.602^{* * *}$ & 21.907 & 0.568 \\
H2. Communication --> Performance & $0.677^{* * *}$ & 24.448 & 1.045 \\
H3. Legitimacy --> Performance & $0.246^{* * *}$ & 7.315 & 0.138 \\
R $^{2}$ Legitimacy $=$ 0.36; Performance $=0.72$ & & & \\
Q $^{2}$ Legitimacy $=$ 0.24; Performance $=0.39$ & & & \\
\hline
\end{tabular}

${ }^{* * *} \mathrm{p}<0.01$

The model's predictive accuracy was measured by the coefficient of determination $\left(\mathrm{R}^{2}\right.$ value). The coefficient represents the amount of explained variance of the endogenous constructs in the structural model. The $\mathrm{R}^{2}$ values show the mean predictive accuracy levels of the model (between 0.25 and 0.75) (Hair et al., 2011). Hospital communication accounts for $38 \%$ of the legitimacy obtained. Communication and legitimacy account for $70 \%$ of hospital performance.

In addition to evaluating the $\mathrm{R}^{2}$ values of all endogenous constructs, the size of the effect $\left(f^{2}\right)$ also verified the suitability of the proposed model. This coefficient measures whether an independent latent variable has a substantial effect on a dependent latent variable. The impact effect can be small (from 0.02 to 0.15 ), medium $(0.15$ to 0.35$)$, or large $(>0.35)$, respectively (Chin, 1998). The results of the model show that communication has a large effect on legitimacy $\left(f^{2}=0.598\right)$ and on hospital performance $\left(f^{2}=0.937\right)$. A small effect of legitimacy on hospital performance is also shown $\left(f^{2}=0.115\right)$.

Furthermore, the Stone-Geisser test or $\mathrm{Q}^{2}$ (Geisser 1975; Stone 1974) was estimated using the blindfolding procedure (omission distance $\mathrm{D}=7$ ). The larger the $\mathrm{Q}^{2}$, the more relevant the predictive model is. In analogy to the effect-size $\mathrm{f}^{2}$, $\mathrm{Q}^{2}$ values of $0.02,0.15$, and 0.35 reveal a small, medium, or large predictive relevance of a certain latent variable (Hair et al., 2017). The results of the model show a moderate predictive relevance of communication to hospital legitimacy, as well as a high predictive relevance of the model in relation to hospital performance.

\section{Discussion and Implications}

This study examined a structural model in which communication, legitimacy, and organizational performance are related. Hypothesis 1 predicted that communication has a positive impact on organizational legitimacy. 
The results confirmed the hypothesis (H1: $\beta=0.602, p<0.01)$. The study empirically demonstrated the effect of communication on organizational legitimacy. On this point it was proven that communication is a variable with moderate predictive relevance $\left(Q^{2}\right)$ that exerts a strong impact $\left(\mathrm{f}^{2}\right)$ on legitimacy. These findings provide empirical evidence on the relationship between communication and the legitimacy of organizations, broadening our understanding of the antecedents of legitimacy in the context of hospitals.

Until now, it was known that some organizational characteristics influenced organizational legitimacy (age, size, niche specialism, government ownership) (Ruef \& Scott, 1998). This research goes further by providing evidence on organizational policies that favor organizational legitimacy. It shows that organizations with good communication systems can generate a consensus among stakeholders, regarding the adequacy of organizational activities. Consensus on knowledge, culture, and social norms determines the legitimacy of organizations. This is achieved thanks to the daily interaction between the organization's members (Walsh \& Ungson, 1991), because the interactions give validity to the system and consequently its ability to influence. Furthermore, this consensus can be manipulated and driven through a communication system capable of generating numerous interactions between stakeholders, since the effect of communication on legitimacy in the context of hospitals is very high.

Hypotheses 2 and 3 of the study proposed a positive effect of communication and legitimacy on organizational performance. Both hypotheses were confirmed (H2: $\beta=0.677, \mathrm{p}<0.01$, H3: $\beta=0.246, p<0.01)$. The study shows the impact of communication and legitimacy on improving organizational performance. It was confirmed that both variables have a positive influence on the performance of public hospitals, especially communication. These results provide empirical evidence on two antecedents of organizational performance. In addition, they expand the knowledge we have about the effects of communication and legitimacy on organizations. In the context of this research, the effect produced by communication on hospital performance is considerably greater than that produced by organizational legitimacy. In highly institutionalized environments, where public interests converge with conformity with social norms and the durability (over time) of the organizations (hospitals), legitimacy is a necessary condition that is taken for granted (Cruz-Suárez, Prado-Román, \& Díez-Martín, 2014), generating a smaller effect on the expected performance. Nevertheless, both antecedents are significant in improving hospital performance.

\section{I Managerial implications}

The study presents new insights for industry and practitioners. Organizational legitimacy has been shown to be a key element to obtain favorable performance in organizations. In highly institutionalized environments such as public hospitals, obtaining legitimacy depends to a large extent on communication. To ensure legitimacy, organizational managers should devote efforts to creating and maintaining a good internal and external communication system. This will allow not only improvements in organizational legitimacy, but will also generate a mechanism with which to manage patients' and employees' behavior. Legitimacy provides a framework for decision-making that is different from other rational methods. Individuals' decisions are influenced by the belief that the decisions of other legitimized organizations or people are correct or appropriate and must be followed (Zelditch, 2001). In this sense, the most legitimized organizations will find it easier to develop their activities, since they will receive greater support from their stakeholders. On the other hand, a lack of legitimacy can lead to a systematic questioning of organizational activities, negatively affecting the implementation of processes. 


\section{Limitations and Future Lines of Research}

The sample for this study came from public hospitals in Madrid (Spain), where the health system is mandatory for the entire population, in the sense that all workers are obliged to contribute to its maintenance. In addition, it is freely accessible, both for workers and for the unemployed. All this has an impact on the generation of a highly institutionalized system, which can influence stakeholders' behavior and performance. Future studies could analyze the effect of communication on legitimacy between different health systems and between different countries. In this way, it would be possible to check the moderating effect of stakeholders in different environmental conditions. In addition, they could also examine the multidimensional aspects of legitimacy, which include the pragmatic, moral, regulatory, cognitive, and emotional dimensions (see Díez-de-Castro et al., 2018). That is, they could examine how communication influences different types of legitimacy. The interest of this analysis lies in the possibility of designing communication actions aimed at achieving a specific type of legitimacy. Studies suggest that each type of legitimacy has different effects on the results of organizations (Díez-Martín et al., 2013). Therefore, managers would be more interested in achieving the type of legitimacy associated with better results.

Personal characteristics (e.g. social consciousness, trust) influence legitimacy assessments (Bitektine \& Haack, 2015; DíezMartín et al., 2018). The present study did not consider how communication influences people with different personal characteristics, and the effect this produces on legitimacy assessments. Along these lines, future research could analyze the moderating effect produced by personal characteristics between communication and legitimacy. It would be particularly interesting to analyze the moderating effect of gender, to determine if there are significant differences between evaluators of different genders when analyzing the legitimacy of companies. This could be of special interest to managers when designing their communication campaigns.

The research carried out a global evaluation of communication in hospitals, without emphasizing specific aspects of the communication system, such as the means used or the vocabulary used. Future research could analyze how the media influences the construction of hospital legitimacy. What is the effect of communication channels, narrative, or storytelling on hospital legitimacy? (Cho et al., 2010; Golant \& Sillince 2007).

The proposed structural model suggests a positive communication-legitimacy-performance relationship. The results indicate that legitimacy influences hospital performance, although to a lesser extent than the effect produced by communication. On this point, future studies could consider to what extent legitimacy is a mediator variable, capable of enhancing the effect of communication on hospital performance.

\section{References}

Aerts, W., \& Cormier, D. (2009). Media legitimacy and corporate environmental communication. Accounting, Organizations and Society, 34(1), 1-27.

Alexiou, K., \& Wiggins, J. (2018). Measuring individual legitimacy perceptions: Scale development and validation. Strategic Organization, 17(4), 270-496. doi: $10.1177 / 1476127018772862$

Ashcraft, K. L., Kuhn, T. R., \& Cooren, F. (2009). Constitutional amendments: "Materializing" organizational communication. Academy of Management Annals, 3(1), 1-64.

Baird, K. M., Tung, A., \& Yu, Y. (2017). Employee organizational commitment and hospital performance. Health Care Management Review, 44(3), 206-215. doi: 10.1097/ HMR.0000000000000181 
Bansal, P., \& Clelland, I. (2004). Talking trash: Legitimacy, impression management, and unsystematic risk in the context of the natural environment. Academy of Management Journal, 47(1), 93-103.

Becker-Blease, J. R., \& Sohl, J. E. (2015). New venture legitimacy: The conditions for angel investors. Small Business Economics, 45(4), 735-749.

Bell, R. G., Filatotchev, I., \& Aguilera, R. V. (2013). Corporate governance and investors' perceptions of foreign IPO value: An institutional perspective. Academy of Management Journal, 57(1), 301-320. doi:10.5465/amj.2011.0146

Bitektine, A. (2011). Toward a theory of social judgments of organizations: The case of legitimacy, reputation, and status. The Academy of Management Review, 36(1), 151-179.

Bitektine, A., \& Haack, P. (2015). The macro and the micro of legitimacy: Towards a multi-level theory of the legitimacy process. Academy of Management Review, 40(1), 49-75. doi:10.5465/ amr.2013.0318

Brown, A. D. (1998). Narrative, politics and legitimacy in an IT implementation. Journal of Management Studies, 35(1), 35-58.

Camilleri, M. A. (2018). Theoretical insights on integrated reporting. Corporate Communications: An International Journal, 23(4), 567-581.

Chaney, D., Lunardo, R., \& Bressolles, G. (2016). Making the store a place of learning: The effects of in-store educational activities on retailer legitimacy and shopping intentions. Journal of Business Research, 69(12), 5886-5893.

Chang, W.-C., Tung, Y.-C., Huang, C.-H., \& Yang, M.-C. (2008). Performance improvement after implementing the Balanced Scorecard: A large hospital's experience in Taiwan. Total Quality Management \& Business Excellence, 19(11), 11431154.

Chattopadhyay, P., Glick, W. H., Miller, C. C., \& Huber, G. P. (1999). Determinants of Executive Beliefs: Comparing Functional Conditioning and
Social Influence. Strategic Management Journal, 20(8), 763-789.

Chin, W. W. (1998). The partial least squares approach to structural equation modeling. In G. A. Marcoulides (Ed.), Modern Methods for Business Research (Quantitative Methodology Series, Cap. 10, pp. 295-336). Mahwah, NJ: Lawrence Erlbaum Associates.

Cho, C. H., \& Patten, D. M. (2007). The role of environmental disclosures as tools of legitimacy: A research note. Accounting, Organizations and Society, 32(7/8), 639-647.

Cho, C. H., Roberts, R. W., \& Patten, D. M. (2010). The language of US corporate environmental disclosure. Accounting, Organizations and Society, 35(4), 431-443.

Choi, Y. R., \& Shepherd, D. A. (2005). Stakeholder perceptions of age and other dimensions of newness. Journal of Management, 31(4), 573-596.

Cornelissen, J. P., Durand, R., Fiss, P. C., Lammers, J. C., \& Vaara, E. (2015). Putting communication front and center in institutional theory and analysis. Academy of Management Review, 4O(1), 10-27.

Cruz-Suárez, A., Prado-Román, C., \& DíezMartín, F. (2014). Por qué se institucionalizan las organizaciones. Revista Europea de Dirección y Economía de La Empresa, 23(1), 22-30.

Dahlgaard, J. J., Pettersen, J., \& Dahlgaard-Park, S. (2011). Quality and lean health care: A system for assessing and improving the health of healthcare organisations. Total Quality Management \& Business Excellence, 22(6), 673-689.

Deegan, C. (2002). Introduction: The legitimising effect of social and environmental disclosures - a theoretical foundation. Accounting, Auditing \& Accountability Journal, 15(3), 282-311.

Deephouse, D. L. (1996). Does isomorphism legitimate? Academy of Management Journal, 39(4), 1024-1039.

Deephouse, D. L., Bundy, J., Tost, L. P., \& Suchman, M. C. (2017). Organizational 
Legitimacy: Six Key Questions. In R. Greenwood, C. Oliver, T. B. Lawrence, \& R. Meyer (Eds.), The Sage Handbook of Organizational Institutionalism (2nd ed., Cap. 1, pp. 28-54). Thousand Oaks CA: Sage.

Deephouse, D. L., \& Suchman, M. (2008). Legitimacy in organizational institutionalism. In R. Greenwood, C. Oliver, R. Suddaby, \& K. Sahlin. (Eds.), The Sage Handbook Of Organizational Institutionalism (Cap. 1, pp. 4977). Los Angeles CA: Sage Publications.

Desmidt, S., \& George, B. (2016). Do we see eye to eye? The relationship between internal communication and between-group strategic consensus. Management Communication Quarterly, 30(1), 84-102.

Díez-de-Castro, E., Peris-Ortiz, M., \& DíezMartín, F. (2018). Criteria for evaluating the organizational legitimacy: A Typology for legitimacy jungle. In E. Díez-de-Castro \& $\mathrm{M}$. Peris-Ortiz (Eds.), Organizational Legitimacy: Challenges and Opportunities for Businesses and instituons (Cap. 1, pp. 1-21). Cham, Switzerland : Springer International Publishing.

Díez-Martín, F., Blanco-González, A., \& PradoRoman, C. (2018). Factors affecting individual decisions based on business legitimacy. Journal of Promotion Management, 25(2), 181-199. doi: $10.1080 / 10496491.2018 .1443308$

Díez-Martín, F., Prado-Roman, C., \& BlancoGonzález, A. (2013). Beyond legitimacy: Legitimacy types and organizational success. Management Decision, 51(10), 1954-1969.

DiMaggio, P., \& Powell, W. W. (1983). The iron cage revisited: Institutional isomorphism and collective rationality in organizational fields. American Sociological Review, 48(2), 147-160.

Dowling, J., \& Pfeffer, J. (1975). Organizational legitimacy: social values and organizational behavior. The Pacific Sociological Review, 18(1), 122-136.

Drori, I., \& Honig, B. (2013). A Process model of internal and external legitimacy. Organization Studies, 34(3), 345-376.
Elsbach, K. D. (1994). Managing organizational legitimacy in the California cattle industry: The construction and effectiveness of verbal accounts. Administrative Science Quarterly, 39(1), 57-58.

Fornell, C., \& Larcker, D. F. (1981). Evaluating structural equation models with unobservable variables and measurement error. Journal of Marketing Research, 18(1), 39-50.

Geisser, S. (1975). The predictive sample reuse method with applications. Journal of the American Statistical Association, 70(350), 320-328.

Golant, B. D., \& Sillince, J. A. A. (2007). The Constitution of organizational legitimacy: A narrative perspective. Organization Studies, 28(8), 1149-1167.

Gómez-Martínez, R., Andreu, L., \& DíezMartín, F. (2018). Explanation of the relation between organizational legitimacy and firms' price. In E. Díez-de-Castro \& M. Peris-Ortiz (Eds.) Organizational legitimacy: Challenges and opportunities for businesses and instituons (Cap. 17, pp. 271-281). Cham, Switzerland: Springer International Publishing.

Hair, J. F., Jr., Hult, G. T. M., Ringle, C. M., \& Sarstedt, M. (2017). A Primer on partial least squares structural equation modeling (2nd ed.). Thousand Oaks, CA: Sage.

Hair, J. F., Jr., Ringle, C. M., \& Sarstedt, M. (2011). PLS-SEM: Indeed a Silver Bullet. Journal of Marketing Theory and Practice, 19(2), 139-152.

Hannan, M. T., \& Carroll, G. (1992). Dynamics of organizational populations: Density, legitimation, and competition. New York: Oxford University Press.

Henseler, J., Ringle, C., \& Sarstedt, M. (2015). A new criterion for assessing discriminant validity in variance-based structural equation modeling. Journal of the Academy of Marketing Science, 43(1), 115-135.

Kersten, A. (1986). A critical-interpretive approach to the study of organizational communication: bring communication back into the field. In L. Thayer (Ed.), Organization and communication: 
emerging perspective (Vol. 1, pp. 133-150). Norwood, NJ: Ablex Publishing.

König, A., Fehn, A., Puck, J., \& Graf-Vlachy, L. (2017). Primary or complex? Towards a theory of metaphorical strategy communication in MNCs. Journal of World Business, 52(2), 270-285.

Kostova, T., Roth, K., \& Dacin, M. T. (2008). Institutional theory in the study of multinational corporations: A critique and new directions. Academy of Management Review, 33(4), 994-1006.

Lamin, A., \& Zaheer, S. (2012). Wall Street vs. Main Street: Firm strategies for defending legitimacy and their impact on different stakeholders. Organization Science, 23(1), 47-66.

Lock, I., \& Schulz-Knappe, C. (2019). Credible corporate social responsibility (CSR) communication predicts legitimacy. Corporate Communications: An International Journal, 24(1), 2-20.

Mártinez-Navalón, J-G., Blanco-González, A., \& Prado-Román, A. (2019) An analysis of stakeholders satisfaction and legitimacy: The business model of the university institution. Revista Espacios, 40(16), 27-38.

McDermott, C., \& Boyer, K. K. (1999). Strategic consensus: Marching to the beat of a different drummer? Business Horizons, 42(4), 21-28.

McPherson, C. M., \& Sauder, M. (2013). Logics in action: Managing institutional complexity in a drug court. Administrative Science Quarterly, 58(2), 165-196.

Meyer, J. W., \& Rowan, B. (1977). Institutionalized organizations: Formal structure as myth and ceremony. American Journal of Sociology, 83(2), 340-363.

Ministerio de Sanidad. (2016). Plan de calidad para el sistema nacional de salud. Retrieved January 12, 2017, from https://www.msssi.gob.es/ organizacion/sns/planCalidadSNS/pncalidad.htm

Mitchell, R. K., Agle, B. R., \& Wood, D. J. (1997). Toward a theory of stakeholder Identification and salience: Defining the principle of who and what really counts. Academy of Management Review, 22(4), 853-886.
Noble, C. H. (1999). The Eclectic Roots of Strategy Implementation research. Journal of Business Research, 45(2), 119-134.

Nunnally, J. C., \& Bernstein, I. (1994). Psychometric Theory. (3rd ed.). United States: McGraw Hill.

Oliver, C. (1991). Strategic responses to institutional processes. Academy of Management Review, 16(1), 145-179.

Palazzo, G., \& Scherer, A. G. (2006). Corporate legitimacy as deliberation: A communicative framework. Journal of Business Ethics, 66(1), 71-88.

Piber, M., Demartini, P., \& Biondi, L. (2019). The management of participatory cultural initiatives: Learning from the discourse on intellectual capital. Journal of Management and Governance, 23(2), 435-458.

Pollack, J. M., Rutherford, M. W., \& Nagy, B. G. (2012). Preparedness and cognitive legitimacy as antecedents of new venture funding in televised business pitches. Entrepreneurship Theory and Practice, 36(5), 915-939.

Rapert, M. I., Velliquette, A., \& Garretson, J. A. (2002). The strategic implementation process: evoking strategic consensus through communication. Journal of Business Research, 55(4), 301-310.

Rapert, M. I., \& Wren, B. M. (1998). Reconsidering organizational structure: A dual perspective of frameworks and processes. Journal of Managerial Issues, 10(3), 287-302

Reinartz, W., Haenlein, M., \& Henseler, J. (2009). An empirical comparison of the efficacy of covariance-based and variance-based SEM. International Journal of Research in Marketing, 26(4), 332-344.

Ross, W. T., Jr., Anderson, E., \& Weitz, B. (1997). Performance in principal-agent dyads: The causes and consequences of perceived asymmetry of commitment to the relationship. Management Science, 43(5), 680-704. 
Ruef, M., \& Scott, W. R. (1998). A multidimensional model of organizational legitimacy: Hospital survival in changing institutional environments. Administrative Science Quarterly, 43(4), 877-904.

Scherer, A. G., \& Palazzo, G. (2007). Toward a political conception of corporate responsibility: business and society seen from a habermasian perspective. Academy of Management Review, 32(4), 1096-1120.

Siam, M. R. A. (2017). The effect of communication strategy on the relationship between strategy execution (organisational level) and organisational performance: A middle level managers' perspective at higher education institutions. Journal for Global Business Advancement, 10(2), 158.

Skivington, J. K., \& Daft, R. L. (1991). A study of organizational framework and process modalities for the implementation of business-level strategic decisions. Journal of Management Studies, 28(1), 45-68.

Stone, M. (1974). Cross-validatory choice and assessment of statistical predictions. Journal of the Royal Statistical Society, 36(2), 111-147.

Suchman, M. C. (1995). Managing legitimacy: strategic and institutional approaches. Academy of Management Review, 20(3), 571-610.

Suddaby, R. (2010). Challenges for Institutional Theory. Journal of Management Inquiry, 19(1), 14-20.

Suddaby, R., Bitektine, A., \& Haack, P. (2017). Legitimacy. Academy of Management Annals, 11(1), 451-478.

Suddaby, R., \& Greenwood, R. (2005). Rhetorical strategies of legitimacy. Administrative Science Quarterly, 50(1), 35-67.

Tornikoski, E. T., \& Newbert, S. L. (2007). Exploring the determinants of organizational emergence: A legitimacy perspective. Journal of Business Venturing, 22(2), 311-335.
Tost, L. P. (2011). An integrative model of legitimacy judgments. Academy of Management Review, 36(4), 686-710.

Vaara, E., \& Tienari, J. (2008). A discursive perspective on legitimation strategies in MNCs. Academy of Management Review, 33(4), 985-993.

Voelker, K. E., Rakich, J. S., \& French, G. R. (2001). The Balanced Scorecard in healthcare organizations: A performance measurement and strategic planning methodology. Hospital Topics, 79(3), 13-24.

Walsh, J. P., \& Ungson, G. R. (1991). Organizational memory. Academy of Management Review, 16(1), 57-91

Wynia, M. K., \& Osborn, C. Y. (2010). Health Literacy and Communication Quality in Health Care Organizations. Journal of Health Communication, 15(suppl. 2), 102- 115.

Yim, M. C., \& Park, H. S. (2019). Why legitimacy matters in crisis communication: A case study of the "Nut Rage" incident on Korean Air. Journal of Business and Technical Communication, 33(2), 172-202.

Zelditch, M. (2001). Processes of legitimation: Recent developments and new directions. Social Psychology Quarterly, 64(1), 4-17.

Zilber, T. B. (2006). The work of the symbolic in institutional processes: Translations of rational myths in Israeli high tech. Academy of Management Journal, 49(2), 281-303.

Zimmerman, M. A., \& Zeitz, G. J. (2002). Beyond survival: Achieving new venture growth by building legitimacy. Academy of Management Review, 27(3), 414.

Zwijze-Koning, K., \& Jong, M. de (2007). Evaluating the Communication Satisfaction Questionnaire as a Communication Audit Tool. Management Communication Quarterly, 20(3), 261-282. 


\section{Appendix}

Survey questionnaire.

All variables are based on five-point Likert scales.

\begin{tabular}{|c|c|c|}
\hline Dimension & Item ID & Question \\
\hline \multicolumn{3}{|l|}{ Communication } \\
\hline Internal communication & Com 1 & How good is the communication between the hospital and patients? \\
\hline External communication & Com 2 & How good is the communication between the hospital personnel? \\
\hline \multicolumn{3}{|l|}{ Legitimacy } \\
\hline & & The activities performed by your hospital: \\
\hline Pragmatic & Leg 1 & ...are useful. \\
\hline Moral & Leg 2 & ...are "the right thing to do." \\
\hline Cognitive & Leg 3 & ...are done the best way possible. \\
\hline \multicolumn{3}{|l|}{ Performance } \\
\hline & & What is your perception of: \\
\hline & Perf 1 & equal treatment between patients? \\
\hline & Perf 2 & patient care? \\
\hline & Perf 3 & satisfaction of patient needs? \\
\hline & Perf 4 & the use of hospital resources? \\
\hline & Perf 5 & the image of the hospital? \\
\hline & Perf 6 & staff training? \\
\hline
\end{tabular}




\section{Authors:}

1. Camilo Prado-Roman, PhD, Rey Juan Carlos University, Madrid, Spain. camilo.

E-mail: prado.roman@urjc.es

\section{ORCID}

(iD) 0000-0002-1540-0643

2. Francisco Diez-Martin, PhD, Rey Juan Carlos University, Madrid, Spain.

E-mail: francisco.diez@urjc.es

ORCID

(iD) 0000-0002-9888-833X

3. Alicia Blanco-Gonzalez, PhD, Rey Juan Carlos University, Madrid, Spain.

E-mail: alicia.blanco@urjc.es

ORCID

(iD) 0000-0002-8509-7993

\section{Contribution of each author}

\begin{tabular}{|c|c|c|c|}
\hline Contribution & $\begin{array}{c}\text { Camilo } \\
\text { Prado-Roman }\end{array}$ & $\begin{array}{c}\text { Francisco } \\
\text { Diez-Martin }\end{array}$ & $\begin{array}{c}\text { Alicia Blanco- } \\
\text { Gonzalez }\end{array}$ \\
\hline 1. Definition of research problem & $\sqrt{ }$ & $\sqrt{ }$ & $\sqrt{ }$ \\
\hline 2. Development of hypotheses or research questions (empirical studies) & $\sqrt{ }$ & $\sqrt{ }$ & $\sqrt{ }$ \\
\hline 3. Development of theoretical propositions (theoretical work) & $\sqrt{ }$ & $\sqrt{ }$ & $\sqrt{ }$ \\
\hline 4. Theoretical foundation / Literature review & $\sqrt{ }$ & $\sqrt{ }$ & $\sqrt{ }$ \\
\hline 5. Definition of methodological procedures & & $\sqrt{ }$ & $\sqrt{ }$ \\
\hline 6. Data collection & $\sqrt{ }$ & $\sqrt{ }$ & $\sqrt{ }$ \\
\hline 7. Statistical analysis & $\sqrt{ }$ & $\sqrt{ }$ & \\
\hline 8. Analysis and interpretation of data & $\sqrt{ }$ & & $\sqrt{ }$ \\
\hline 9. Critical revision of the manuscript & & $\sqrt{ }$ & $\sqrt{ }$ \\
\hline 10. Manuscript writing & $\sqrt{ }$ & $\sqrt{ }$ & \\
\hline 11. Other (please specify which) & & & \\
\hline
\end{tabular}

